\title{
Optimization of Ultrasound-Assisted Extraction of Bioactive Compounds from Pelvetia canaliculata to Sunflower Oil
}

\author{
Gabriela Sousa ${ }^{1}$, Marija Trifunovska ${ }^{1,2}$, Madalena Antunes ${ }^{3}$, Isabel Miranda ${ }^{4}$, Margarida Moldão ${ }^{1}$ (D), \\ Vítor Alves ${ }^{1}\left(\mathbb{D}\right.$, Rajko Vidrih ${ }^{2}$, Paula Allen Lopes ${ }^{5}$, Luis Aparicio ${ }^{5}$, Marta Neves ${ }^{3} \mathbb{D}$, Carla Tecelão ${ }^{3}$ (D) \\ and Suzana Ferreira-Dias $1, * \mathbb{D}$
}

\section{check for} updates

Citation: Sousa, G.; Trifunovska, M.; Antunes, M.; Miranda, I.; Moldão, M.; Alves, V.; Vidrih, R.; Lopes, P.A.; Aparicio, L.; Neves, M.; et al. Optimization of Ultrasound-Assisted Extraction of Bioactive Compounds from Pelvetia canaliculata to Sunflower Oil. Foods 2021, 10, 1732. https:// doi.org/10.3390/foods10081732

Academic Editors: Amalia Piscopo and Antonella Pasqualone

Received: 20 June 2021

Accepted: 22 July 2021

Published: 27 July 2021

Publisher's Note: MDPI stays neutral with regard to jurisdictional claims in published maps and institutional affiliations.

Copyright: (c) 2021 by the authors. Licensee MDPI, Basel, Switzerland. This article is an open access article distributed under the terms and conditions of the Creative Commons Attribution (CC BY) license (https:// creativecommons.org/licenses/by/ $4.0 /)$.
1 LEAF_-Linking Landscape, Environment, Agriculture and Food-Research Center, Instituto Superior de Agronomia, Universidade de Lisboa, 1349-017 Lisbon, Portugal; gabriela.spsousa@gmail.com (G.S.); trifunovska93@hotmail.com (M.T.); mmoldao@isa.ulisboa.pt (M.M.); vitoralves@isa.ulisboa.pt (V.A.)

2 Biotechnical Faculty, University of Ljubljana, 1000 Ljubljana, Slovenia; rajko.vidrih@bf.uni-lj.si

3 MARE-Marine and Environmental Sciences Centre, Politécnico de Leiria, 2520-641 Peniche, Portugal; madalena.f.antunes@ipleiria.pt (M.A.); marta.neves@ipleiria.pt (M.N.); carla.tecelao@ipleiria.pt (C.T.)

4 Centro de Estudos Florestais, Instituto Superior de Agronomia, Universidade de Lisboa, 1349-017 Lisbon, Portugal; imiranda@isa.ulisboa.pt

5 Sovena Group, 1495-131 Algés, Portugal; paula.allen.lopes@sovena.pt (P.A.L.); Luis.aparicio@sovena.es (L.A.)

* Correspondence: suzanafdias@mail.telepac.pt

Abstract: In this study, Pelvetia canaliculata L. macroalga, collected from the Atlantic Portuguese coast, was used as a source of bioactive compounds, mostly antioxidants, to incorporate them in sunflower oil with the aim of increasing its biological value and oxidative stability. The lyophilized alga was added to the oil, and ultrasound-assisted extraction (UAE) was performed. Algae concentration and UAE time varied following a central composite rotatable design (CCRD) to optimize extraction conditions. The following parameters were analyzed in the oils: oxidation products, acidity, color, chlorophyll pigments, carotenoids, flavonoids, total phenolic content, antioxidant activity by DPPH (2,2-diphenyl-1-picrylhydrazyl) and FRAP (ferric reducing antioxidant power) assays, and sensory analysis. Extraction conditions did not affect the acidity and the amount of oxidation products in the oil. Chlorophylls and carotenoid contents increased with algae concentration, while flavonoid extraction did not depend on algae content or UAE time. Total phenolics in the oil were highly related only to FRAP antioxidant activity. Storage experiments of supplemented oil ( $12.5 \%$ algae; 20 min UAE) were carried out under accelerated oxidation conditions at $60{ }^{\circ} \mathrm{C} / 12$ days. Antioxidant activity (FRAP) of supplemented oil was 6-fold higher than the value of non-supplemented oil. Final samples retained $40 \%$ of their initial antioxidant activity. The presence of algae extracts contributed to the increased oxidative stability of sunflower oil.

Keywords: algae; antioxidants; bioactive compounds; oxidative stability; Pelvetia canaliculata; response surface methodology; sunflower oil; ultrasound-assisted extraction

\section{Introduction}

Sunflower (Helianthus annuus L.) oil is obtained by physical or chemical ( $n$-hexane) extraction of the sunflower seeds. This oil has wide culinary uses, i.e., for cooking, bakery, and frying. It is also used in the food industry for frying, production of emulsions, sauces, spreads, fillings, and in many different food formulations, namely margarine and mayonnaise.

The worldwide production of sunflower oil in 2018/2019 reached 19.34 million metric tons, which puts sunflower oil in fourth place of the most used oils in food, after palm, soybean, and rapeseed oils [1]. Therefore, the improvement of both the quality and stability of sunflower oil are central points for the food industry. 
The limited oxidative stability of edible oils is one of the main constraints for the food industry, leading to a loss of nutritional value, a decrease in shelf-life, and the development of undesirable flavors. The resistance of edible oils to oxidation during processing, handling, and storage is related to their fatty acid composition, antioxidant content, and processing, storage, and handling conditions [2]. Sunflower oil is rich in polyunsaturated (PUFA) linoleic acid, C18:2 (48.3-74.0\%) and monounsaturated (MUFA) oleic acid, C18:1 (14.0-39.4\%) [3-5]. Since PUFA are more prone to oxidation, the high content of linoleic acid in sunflower oil will inevitably affect its oxidative stability [6].

To improve oxidative stability and to maintain the nutritional and sensory properties of refined oils, antioxidants are widely used in the food industry, following specific and tight legislation $[3,7,8]$. In addition to natural antioxidants, such as tocopherols, synthetic antioxidants, namely tertiary butyl hydroquinone (TBHQ), butylated hydroxyanisole (BHA), and butylated hydroxytoluene (BHT), can also be used [3].

Recently, the search for natural sources of antioxidants is increasing due to toxicological effects associated with synthetic ones [9]. Therefore, the supplementation of edible oils with natural antioxidants (namely from herbs, fruits, seeds, and processing by-products) has gained increasing interest in the last years [10-12].

Previous studies showed that the addition of natural antioxidants to sunflower oil improves its oxidative stability. In this context, rosemary (Rosmarinus officinalis L.) essential oil [13], Salix aegyptiaca L. extracts and essential oil [14], and Pterospartum tridentatum (L.) Willk. ethanolic extracts [15] were used to prevent the oxidation of sunflower oils.

Algae are known to be a source of valuable natural compounds, namely, polysaccharides, vitamins, proteins, steroids, dietary fibers, and natural antioxidants, which can be applied to cosmetics, food production, and food supplements [16-20]. Pelvetia canaliculata L. is a brown alga widely present on the Atlantic coast of Portugal [21]. This alga is rich in bioactive compounds, especially in phenolic compounds [22-25]. In addition, it has the advantage of lacking lignin, which makes easier the extraction of the interested biomolecules [26]. In the last years, the use of eco-friendly methods, such as ultrasound-assisted extraction (UAE), as an alternative to solvent extraction methods to recover bioactive compounds, is increasing $[27,28]$.

The aim of this study was to enhance the nutritional quality and oxidative stability of refined sunflower oil by supplementation with bioactive compounds, predominantly antioxidants, from P. canaliculata directly to the oil by ultrasound-assisted extraction (UAE). The effect of UAE time and concentration of algae on oil oxidative stability, as well as on the content of bioactive compounds, were evaluated by response surface methodology (RSM), following a central composite rotatable design (CCDR). The oxidative stability of supplemented sunflower oil, obtained under selected UAE conditions, was also evaluated at $60^{\circ} \mathrm{C}$.

\section{Materials and Methods}

\subsection{Materials}

Refined sunflower oil without added antioxidants was kindly donated by SOVENA Portugal, Consumer Goods SA. The brown macroalga Pelvetia canaliculata L. was harvested at the beach of Pedras do Corgo, Portugal (41 $14^{\prime} 55.52^{\prime \prime}$ N, $8^{\circ} 43^{\prime} 29.89^{\prime \prime}$ W) in June 2019. Gallic acid (97.5\% purity), Trolox (97\% purity), quercetin (95\% purity), and catechin (98\% purity) used for calibration curves were purchased from Sigma and Acros Organics. All the solvents and reagents used were analytical grade and obtained from different suppliers.

\subsection{Characterization of Pelvetia canaliculata}

Algae biomass was characterized regarding (i) proximate composition (total protein, lipids, carbohydrates, and ash), (ii) pigments (chlorophyll and carotenoid contents) in n-hexane extracts, (iii) total phenolic compounds and flavonoids in methanol extracts, and (iv) antioxidant activity in methanol extracts. 


\subsubsection{Algae Material and Extracts Preparation}

After harvest, algae material was cleaned from extraneous matter, frozen at $-80{ }^{\circ} \mathrm{C}$ (Haier Biomedical, DW-86L728J, Qingdao, China), freeze-dried (Telstar, Lyoquest-85, Telstar Portugal, Lisbon, Portugal), ground to powder, and stored at $-20^{\circ} \mathrm{C}$ until use. The extracts were prepared by vortex stirring the freeze-dried algae with $n$-hexane $(6.24 \%, m / v)$ or methanol $(6.28 \%, m / v)$ for $6 \mathrm{~min}$. Then, the suspension was centrifuged (10 $\mathrm{min}$ at $3000 \mathrm{rpm})$ to separate the solid residue. Finally, the extracts were stored, protected from light, in the refrigerator at $4{ }^{\circ} \mathrm{C}$, until further analyses.

\subsubsection{Proximate Composition}

Crude protein of freeze-dried P. canaliculata was determined by the Kjeldahl method, using the conversion factor of 5.38, which is specific for brown algae [29].

Total lipid content was analyzed according to Folch et al. [30] with slight modifications. Briefly, lyophilized algae samples $(1 \mathrm{~g})$ were hydrated with $1 \mathrm{~mL}$ of deionized water and extracted with $10 \mathrm{~mL}$ of Folch reagent $\left(\mathrm{CHCl}_{3}: \mathrm{CH}_{3} \mathrm{OH}, 1: 2 \mathrm{v} / \mathrm{v}\right)$ under vortex stirring. After addition of $1.2 \mathrm{~mL}$ of $\mathrm{NaCl} 0.8 \%(\mathrm{~m} / \mathrm{v})$, samples were homogenized and centrifuged ( $5 \mathrm{~min}$ at $6000 \mathrm{rpm}$ ) for phase separation. The lower phase was recovered and filtered through an anhydrous sodium sulfate column to a flask previously weighed. Then, chloroform $(5 \mathrm{~mL})$ was added to the remaining sample material, and the extraction procedure was repeated. Finally, the solvent was removed in a rotary evaporator (Heidolph 2, LAB1ST, Shanghai, China), and the lipid extract was dried at $40{ }^{\circ} \mathrm{C}$ until constant weight. Ash quantification was carried out by incineration of lyophilized algae samples $(500 \mathrm{mg})$ in a muffle (Nabertherm, Liliemthal/Bermen, Germany) at $500{ }^{\circ} \mathrm{C}$ for $12 \mathrm{~h}$. Total carbohydrates were calculated by difference, considering protein, lipids, and ash values. All the results were expressed as mean $\pm \mathrm{STD}$, on a dry weight basis (\% d.w.), of four independent analyses.

\subsubsection{Chlorophyll and Carotenoid Contents}

The chlorophyll content of $n$-hexane extract of Pelvetia canaliculata was determined according to the method described by Pokorny et al. [31], with modifications, and expressed as mg pheophytin a/kg algae (d.w.). The extract was directly analyzed in a UV-Vis double beam spectrophotometer (Agilent Technologies cary series 100 UV-Vis, Santa Clara, CA, USA) by measuring the absorbance in a $5 \mathrm{~mm}$ cell at wavelengths: 630, 670, and $710 \mathrm{~nm}$ using air as reference. Three replicates of each sample were analyzed.

For quantification of carotenoids, the extract was diluted in $n$-hexane in a 1:1 ratio $(v / v)$. Diluted samples were analyzed in a UV-Vis spectrophotometer (Agilent Technologies cary series $100 \mathrm{UV}$-Vis) at $450 \mathrm{~nm}$, using $n$-hexane as a reference, as described by Rougereau et al. [32]. The carotenoid content was quantified as $\mathrm{mg} \beta$-carotene $/ \mathrm{kg}$ algae (d.w.), according to the British Standard B.S. 684, Section 2.20:1977 [33]. Three replicates of each sample were analyzed.

\subsubsection{Total Phenolic Compounds and Total Flavonoids}

The total phenolic content was determined according to the Folin-Ciocalteu method, as described by Matanjun et al. [34]. Methanolic extract of $P$. canaliculata $(0.05 \mathrm{~mL})$ was mixed with $0.05 \mathrm{~mL}$ of methanol, $1.6 \mathrm{~mL}$ of Milli $\mathrm{Q}$ water, and $0.1 \mathrm{~mL}$ Folin-Ciocalteu reagent. The mixture was kept in the dark for $5 \mathrm{~min}$. Then, $0.3 \mathrm{~mL}$ of $20 \%(\mathrm{~m} / \mathrm{v})$ sodium carbonate solution was added, and finally, the mixture was again kept in the dark, at room temperature, for $1 \mathrm{~h}$. After incubation, the absorbance of the solution was measured at wavelength $765 \mathrm{~nm}$ against methanol in a UV/VIS double beam spectrophotometer (Agilent Technologies cary series $100 \mathrm{UV}$-Vis). For the calibration curve, gallic acid was used in concentrations from 0.47 to $19.05 \mu \mathrm{g} / \mathrm{mL}$. Samples were treated following the same procedure. The obtained standard curve had a determination coefficient, $R^{2}$, of 0.994 (10 data points).

For the determination of total flavonoids, $0.25 \mathrm{~mL}$ of methanolic extract of $P$. canaliculata was used in which $0.25 \mathrm{~mL}$ of methanol, $2 \mathrm{~mL} \mathrm{dH} \mathrm{H}_{2} \mathrm{O}$, and $0.15 \mathrm{~mL}$ of $\mathrm{NaNO}_{2} 5 \%(\mathrm{~m} / \mathrm{v})$ 
were added. The mixture was kept in the dark for $5 \mathrm{~min}$. Then, $0.15 \mathrm{~mL}$ of $\mathrm{AlCl}_{3}(10 \%$ $m / v$ ) was added, and the final mixture stayed in the dark for 6 min. Finally, $1 \mathrm{~mL}$ of $\mathrm{NaOH}$ aqueous solution $(4 \% \mathrm{~m} / \mathrm{v})$ and $1.2 \mathrm{~mL}$ of $\mathrm{dH}_{2} \mathrm{O}$ were added, and the mixture was vortexed. The absorbances were determined at $510 \mathrm{~nm}$, using $1 \mathrm{~cm}$ cell, in a UV/VIS double beam spectrophotometer (Agilent Technologies cary series 100 UV-Vis), with distilled water as blank [35]. Two calibration curves were made using quercetin (18 data points; $R^{2}=0.976$ ) and catechin (10 data points; $\left.R^{2}=0.999\right)$. Quercetin and catechin samples were treated following the same procedure. The results were expressed in milligram of catechin or quercetin equivalent $/ \mathrm{kg}$ of algae (d.w.). Three replicates of each sample were analyzed.

\subsubsection{Determination of Antioxidant Activity DPPH Radical Scavenging Assay}

The antioxidant activity by the DPPH (2,2-diphenyl-1-picrylhydrazyl-hydrate) radical scavenging assay was determined as described by Brand-Williams et al. [36]. The reagent was prepared by dissolving $2.7 \mathrm{mg}$ of DPPH in $100 \mathrm{~mL}$ methanol. Then, $3.9 \mathrm{~mL}$ of the freshly prepared DPPH reagent was mixed with $0.1 \mathrm{~mL}$ of methanolic extract of P. canaliculata. The mixture was vortexed and incubated in the dark, at room temperature, for $30 \mathrm{~min}$. After incubation, the absorbance was read at $515 \mathrm{~nm}\left(\mathrm{~A}_{\text {sample }}\right)$ against methanol using a UV/Vis spectrophotometer (Agilent Technologies cary series 100 UV-Vis). Furthermore, the absorbance at $515 \mathrm{~nm}$ for the DPPH reagent $(3.9 \mathrm{~mL})$ with $0.1 \mathrm{~mL}$ of methanol was determined, which corresponds to the maximum absorbance $\left(\mathrm{A}_{\max }\right)$ value in the calculations. The results were expressed as \% radical scavenging activity (\% RSA) that was calculated by the following equation:

$$
\% \text { RSA }=100 \times\left(\mathrm{A}_{\max }-\mathrm{A}_{\text {sample }}\right) / \mathrm{A}_{\max }
$$

For the calibration curve, the synthetic antioxidant Trolox (6-hydroxy-2,5,7,8-tetrame thylchroman-2-carboxylic acid), an analog of vitamin E, was used. For the stock solution, Trolox $(20 \mathrm{mg})$ was dissolved in methanol $(100 \mathrm{~mL})$. The stock solution was diluted in methanol in six different concentrations up to $5.25 \mu \mathrm{g} / \mathrm{mL}$. The standard curve had a determination coefficient of 0.966 , and the results obtained were expressed in the equivalent of Trolox ( $\mathrm{mg} / \mathrm{kg}$ of algae, d.w.). Three replicates of each sample were analyzed.

\section{Ferric Reducing Antioxidant Power (FRAP)}

The antioxidant capacity of the methanolic extract of $P$. canaliculata was estimated spectrophotometrically following the procedure of Benzie and Strain [37] with minor modifications. Ferric to ferrous ion reduction at low $\mathrm{pH}$ causes the formation of a colored ferrous-2,4,6-tri(2-pyridyl)-1,3,5-triazine (TPTZ) complex, which can be monitored at $595 \mathrm{~nm}$. Freshly prepared FRAP reagent was used, which was obtained by mixing $25 \mathrm{~mL}$ of $0.3 \mathrm{M}$ acetate buffer (pH 3.6), $2.5 \mathrm{~mL}$ of $10 \mathrm{mM}$ TPTZ solution, and $2.5 \mathrm{~mL}$ of $20 \mathrm{mM}$ ferric chloride solution. Immediately, $2.7 \mathrm{~mL}$ of FRAP reagent was mixed with $0.09 \mathrm{~mL}$ of the test solution and $0.27 \mathrm{~mL}$ distilled water. Samples were vortexed and incubated in the dark for $30 \mathrm{~min}$ at $37^{\circ} \mathrm{C}$. After incubation, the absorbance was read at $595 \mathrm{~nm}$ against the FRAP reagent.

For the calibration curve, the antioxidant Trolox was used. The stock solution (20 mg Trolox dissolved in $100 \mathrm{~mL}$ methanol) was diluted in methanol in four different concentrations (up to $6.4 \mu \mathrm{g} / \mathrm{mL}$ ). Trolox samples were treated following the same procedure. The results obtained were expressed in the equivalent of Trolox ( $\mathrm{mg} / \mathrm{kg}$ of algae). Three replicates of each sample were analyzed.

\subsection{Ultrasound-Assisted Extraction of Bioactive Compounds to the Sunflower Oil}

Ultrasound-assisted extraction (UAE) of bioactive compounds from lyophilized $P$. canaliculata was performed directly into the oil using an ultrasound bath (Transsonic TS 540; ultrasound frequency of $35 \mathrm{kHz}$ ). The assays were performed according to an experimental central composite rotatable design (CCRD), which allows the use of the 
response surface methodology (RSM). The UAE time and the P. canaliculata concentration varied simultaneously with a minimum number of trials using RSM. This methodology has the advantage of being less expensive and time-consuming than the classical methods and provides the possibility to estimate interactions between factors [38]. In CCRD, five levels for each variable were applied. The use of five levels for each factor/variable allows the fitting of second-order polynomials to the experimental data points and, hence, to fit curved surfaces to the experimental data. The CCRD matrix, as a function of two factors (UAE time and algae load), consists of a group of four factorial points, a group of four star points and four central points (Table 1). The repetition of the central point enables an estimation of the variance of the experimental error, which is assumed to be constant along the experimental domain [39]. In addition to the experiments dictated by the CCRD, one extra sample (sample 13) was prepared and analyzed. Sample 13 consists of sunflower oil submitted for $20 \mathrm{~min}$ to ultrasonic bath and corresponds to the control sample (Table 1).

Table 1. CCRD and blank experiments followed for ultrasound-assisted extraction (UAE) of bioactive compounds from Pelvetia canaliculata to sunflower oil, as a function of UAE time treatment and algae concentration.

\begin{tabular}{|c|c|c|c|c|c|}
\hline & \multirow{2}{*}{ Assay } & [Algae] & UAE Time & \multirow{2}{*}{$\begin{array}{l}\text { [Algae] }(\% m / v) \\
\text { Decoded Values }\end{array}$} & \multirow{2}{*}{$\begin{array}{l}\text { UAE Time (min) } \\
\text { Decoded Values }\end{array}$} \\
\hline & & Coded Value & Coded Value & & \\
\hline \multirow{4}{*}{ Factorial points } & 1 & -1 & -1 & 7.2 & 7.2 \\
\hline & 2 & -1 & 1 & 7.2 & 17.8 \\
\hline & 3 & 1 & -1 & 17.8 & 7.2 \\
\hline & 4 & 1 & 1 & 17.8 & 17.8 \\
\hline \multirow{4}{*}{ Star points } & 5 & $-\sqrt{2}$ & 0 & 5.0 & 12.5 \\
\hline & 6 & $\sqrt{2}$ & 0 & 20.0 & 12.5 \\
\hline & 7 & 0 & $-\sqrt{2}$ & 12.5 & 5.0 \\
\hline & 8 & 0 & $\sqrt{2}$ & 12.5 & 20.0 \\
\hline \multirow{4}{*}{ Central points } & 9 & 0 & 0 & 12.5 & 12.5 \\
\hline & 10 & 0 & 0 & 12.5 & 12.5 \\
\hline & 11 & 0 & 0 & 12.5 & 12.5 \\
\hline & 12 & 0 & 0 & 12.5 & 12.5 \\
\hline Blank & 13 & - & - & 0 & 20.0 \\
\hline
\end{tabular}

The lyophilized alga was added to $40 \mathrm{~mL}$ of sunflower oil in concentrations between $5 \%$ and $20 \%(m / v)$ (Table 1$)$. The samples were vortexed and subsequently subjected to ultrasound-assisted extraction for 5 to $20 \mathrm{~min}$ (Table 1). Then, the samples were centrifuged (10 $\mathrm{min}$ at $3000 \mathrm{rpm}$ ) to separate the solid residue from the supplemented oil. Finally, the supplemented oils were stored, protected from light, in the refrigerator, at $4{ }^{\circ} \mathrm{C}$, until further analyses.

\subsection{Analyses of the Oil}

\subsubsection{Chemical Quality Parameters of Supplemented Sunflower Oils}

The acidity of the original and supplemented oil samples was determined by titration with $0.1 \mathrm{M}$ potassium hydroxide solution, in accordance with the Commission Regulation (EEC) No.2568/91 [40] and was expressed in acid value (mg KOH/g oil). The presence of primary and secondary oxidation products in original and supplemented oil samples was determined in accordance with the Commission Regulation (EEC) No. 2568/91. Three replicates of each sample were analyzed.

\subsubsection{Sensory Analyses of Supplemented Sunflower Oils}

The supplemented sunflower oil samples were submitted to a preliminary sensory analysis to evaluate the presence of off-odors. A group of 7 trained assessors on olive oil sensory analysis was used [40]. Coded samples were presented to the panelists in covered glasses at $28-30{ }^{\circ} \mathrm{C}$. They were asked to smell the samples, detect, describe, and quantify 
the intensity of eventual off-flavors. A discontinuous and structured scale, from 1 (very slight intensity) to 5 (very strong intensity) was used. For all the samples, the mean and the median (as used for virgin olive oil sensory evaluation) of the detected off-flavors were calculated and used as the response of the panel.

\subsubsection{Chlorophyll Pigments and Carotenoids}

The chlorophyll and carotenoid contents of the oil samples were determined as previously described (cf. 2.2.3) and expressed in $\mathrm{mg}$ of pheophytin a/ $\mathrm{kg}$ oil and as $\beta$-carotene $(\mathrm{mg} / \mathrm{kg}$ oil). Three replicates of each sample were analyzed.

\subsubsection{Determination of Chromatic Characteristics}

The color of the samples was analyzed according to the Portuguese Standard NP 937 from 1972 [41]. The method and results are presented as Supplementary Material.

\subsubsection{Determination of Phenolic Compounds Preparation of Phenolic Extracts}

In order to obtain phenolic extracts, $20 \mathrm{~g}$ of oil samples were added to $40 \mathrm{~mL}$ of $n$ hexane and $40 \mathrm{~mL}$ of methanol-water solution $(80: 20, v / v)$ [42]. The mixture was vortexed for $5 \mathrm{~min}$, and the lower methanolic phase was removed from the upper oil phase in a separatory funnel. The second washing of the oil phase was carried out by the addition of $20 \mathrm{~mL}$ of methanol-water solution $(80: 20 ; v / v)$. The mixture was vortexed for $5 \mathrm{~min}$, after which methanolic phases were paper filtrated. Finally, the oil residues in the methanolic phase were removed by washing with $10 \mathrm{~mL}$ of $n$-hexane. The mixture was vortexed for $1 \mathrm{~min}$ and centrifuged for $10 \mathrm{~min}$ under $3500 \mathrm{rpm}$. After centrifugation, the upper layer (oil phase) was removed from the methanolic phase. The methanolic phase was evaporated until dry matter at $40{ }^{\circ} \mathrm{C}$ and $30 \mathrm{mbar}$ [42]. Dry matter was stored at $-18^{\circ} \mathrm{C}$ until further analyses. Immediately before the subsequent analyses, these samples were dissolved in $2 \mathrm{~mL}$ of methanol. The quantification of total phenolic compounds and flavonoids and the determination of antioxidant activity were performed in triplicate with these extracts.

Determination of Total Phenolic Compounds and of Total Flavonoids

Total phenolic and total flavonoid contents were determined according to the methods described in Section 2.2.4. and expressed as $\mathrm{mg}$ of gallic acid equivalent $/ \mathrm{kg}$ of supplemented sunflower oil and as $\mathrm{mg}$ of catechin or quercetin equivalent $/ \mathrm{kg}$ of supplemented sunflower oil, respectively.

\subsubsection{Determination of Antioxidant Activity}

Antioxidant activity in supplemented oil samples was determined by the DPPH radical scavenging assay (expressed as equivalent $\mathrm{mg}$ of Trolox $/ \mathrm{kg}$ of supplemented sunflower oil) and by the ferric reducing antioxidant power (expressed as equivalent $\mathrm{mg}$ of Trolox/ $\mathrm{kg}$ of supplemented sunflower oil), following the methods previously described (cf. Section 2.2.5).

\subsection{Accelerated Oxidation Tests}

The oil obtained by supplementation with $12.5 \%$ algae under the highest UAE time (20 min) was submitted to accelerated oxidation conditions. This oil was stored in $10 \mathrm{~mL}$ amber glass flasks (full of oil to avoid contact with oxygen) at $60{ }^{\circ} \mathrm{C}$, in the dark, for 12 days. In parallel, non-supplemented sunflower oil was submitted to the same storage conditions. Aliquots corresponding to individual flasks were collected periodically and chemically analyzed.

\subsection{Statistical Analysis}

The obtained results were used to calculate the linear and quadratic effects of each factor, as well as the interaction (Alga concentration $\times$ UAE time) on each response. A 
response surface described by a second-order polynomial equation was fit to each set of results, using the software "Statistica", version 7, from Statsoft, Tulsa, OK, USA. The significance of the effects of the factors was evaluated by ANOVA, where effects were considered significant when $p \leq 0.05$. However, when the removal of a specific factor with $p>0.05$ resulted in a decrease in the goodness of fit of the model, that factor was retained in the model, as suggested by Haaland [43]. The quality of the adjustment of the fitted models was evaluated by the determination coefficient $\left(\mathrm{R}^{2}\right)$ and by the determination adjusted coefficient $\left(R^{2}\right.$ adj $)[39,43]$. High values of both $R^{2}$ and $R^{2}$ adj suggest a good fit of the model to the experimental data. Values of $\mathrm{R}^{2}$ should be at least higher than 0.75 to have a good fit of the model to the experimental results. When above 0.90 , it indicates a very good fit [43].

\section{Results and Discussion}

\subsection{Pelvetia Canaliculata Characterization}

\subsubsection{Proximate Composition}

P. canaliculata was characterized concerning total protein, lipid, carbohydrates, and ash contents expressed as a percentage of dry weight. The algae biomass was mainly constituted by carbohydrates $(65.76 \% \pm 0.43 \%)$ followed by ash $(21.40 \% \pm 0.04 \%)$, protein $(7.72 \% \pm 0.13 \%)$, and lipids $(5.12 \% \pm 0.41 \%)$. These results are in agreement with previous studies regarding the characterization of $P$. canaliculata collected in Norway [44] and in the United Kingdom [45]. Nevertheless, in the study carried out by Badmus et al. [45], significantly lower amounts of protein (less than $2 \%$ ) were reported, which may be justified by the use of the Bradford method that only quantifies soluble proteins [46].

\subsubsection{Chlorophyll and Carotenoid Pigment Contents}

Chlorophyll pigments are responsible for the green color of many plants and algae. However, when in a food matrix, chlorophyll pigments may act as prooxidants [47]. Carotenoids are natural pigments responsible for yellow and orange colors and antioxidant activity.

The quantification of chlorophyll pigments (expressed as pheophytin a), carotenoids (expressed as $\beta$-carotene) in P. canaliculata was performed, and the results are shown in Table 2. The analysis showed the presence of $602 \mathrm{mg}$ of pheophytin a, and $236 \mathrm{mg}$ of $\beta$-carotene per $\mathrm{kg}$ of lyophilized P. canaliculata. These results were used to calculate the extraction yield of each group of pigments from the algae to the sunflower oil in each experiment.

Table 2. Results for the concentration of chlorophyll and carotenoid pigments in P. canaliculata (d.w.); results are the average of three repetitions; STD = standard deviation.

\begin{tabular}{ccc}
\hline Pigments & Amount (mg/kg Algae) & STD \\
\hline $\begin{array}{c}\text { Chlorophyll } \\
\text { [pheophytin a] }\end{array}$ & 602 & 30 \\
\hline $\begin{array}{c}\text { Carotenoids } \\
{[\beta \text {-carotene] }}\end{array}$ & 236 & 12 \\
\hline
\end{tabular}

Hupel et al. [48] determined chlorophyll and carotenoid contents in Pelvetia canaliculata harvested in France. The authors quantified $480 \mathrm{mg}$ of chlorophyll a/ $\mathrm{kg}$ of dried extract, $130 \mathrm{mg}$ of chlorophyll c/ $\mathrm{kg}$ of dried extract, and $120 \mathrm{mg}$ of $\beta$-carotene $/ \mathrm{kg}$ of dried extract. Thus, the total amount of chlorophylls (a and c) determined by the authors was $610 \mathrm{mg}$ of chlorophyll $/ \mathrm{kg}$ of the dried extract, which is similar to the value obtained in the present study. The carotenoid content determined by Hupel et al. [48] was about twice smaller the value determined in the present study, which can be explained by the use of different methods of extraction and quantification, and by the different environmental conditions that the algae were exposed to. 
3.1.3. Determination of Total Phenolic Compounds, Flavonoids, and Antioxidant Activity

Phenolic compounds are presented by a diverse group of secondary metabolites that abundantly occurs in algae and plants. In addition to their antioxidant activity, they also have a synergistic effect with other antioxidant molecules such as ascorbic acid, $\beta$-carotene, and $\alpha$-tocopherol [49]. Flavonoids are important natural pigments with antioxidant activity. Thus, both carotenoids and flavonoids are attractive compounds for the food industry.

The total phenolic content (expressed in gallic acid), the flavonoids (expressed as quercetin or catechin), and the antioxidant activity, assayed by the DPPH radical scavenging method and by the ferric reducing antioxidant power (FRAP), of $P$. canaliculata methanolic extracts, are shown in Table 3. The alga presented $5544 \mathrm{mg}$ of gallic acid $/ \mathrm{kg}$ of lyophilized algae and flavonoid content of $2966 \mathrm{mg}$ of catechin/ $\mathrm{kg}$ of lyophilized algae (7849 mg of quercetin $/ \mathrm{kg}$ ). Concerning the antioxidant activity, P. canaliculata showed a radical scavenging activity of $86 \%$ ( $895 \mathrm{mg}$ of Trolox $/ \mathrm{kg}$ of lyophilized algae) and antioxidant activity, determined by FRAP assay, of $3592 \mathrm{mg}$ of Trolox/ $\mathrm{kg}$ of lyophilized algae.

Table 3. Concentration of phenolic compounds and antioxidant activity of $P$. canaliculata (d.w.); results are the average of three repetitions; STD = standard deviation.

\begin{tabular}{ccc}
\hline Determination & Amount $(\mathbf{m g} / \mathbf{k g}$ Algae) & STD \\
\hline Total phenolic content [gallic & 5544 & 277 \\
acid] & & \\
Flavonoids & 7849 & 393 \\
[quercetin] & & \\
Flavonoids & 2966 & 148 \\
[catechin] & & \\
DPPH, \% (RSA) & 86 & 5 \\
DPPH, [Trolox] & 895 & 52 \\
FRAP, [Trolox] & 3592 & 180 \\
\hline
\end{tabular}

Hupel et al. [48] determined the total phenolic content of $P$. canaliculata extracts, and the results varied between 5.82 and $8.92 \mathrm{mg}$ of gallic acid/g dried extract, depending on the radiation that the algae were exposed. The phenolic content obtained in the present study (5.544 mg gallic acid/g lyophilized algae) was similar to the lower amount obtained by Hupel et al. [48]. Again, the slight differences may be due to the environmental conditions to which the algae were exposed and to the extraction methods used.

\subsection{Quality Parameters of the Supplemented Sunflower Oil}

The ultrasound-assisted supplementation of sunflower oil with P. canaliculata compounds was conducted according to a CCRD as a function of ultrasound-assisted extraction time and algae concentration (Table 1). The obtained results were used to calculate the linear and quadratic effects of each factor, as well as their interaction effect, on each response and to fit a response surface described by a polynomial equation to each set of results.

\subsubsection{Acidity}

The acidity of an oil is a quality parameter related to the extent of hydrolysis of acylglycerols responsible for the release of free fatty acids. In the present study, the acidity assayed as acidity value (mg KOH/g oil) varied from 0.08 to $0.16 \mathrm{mg} \mathrm{KOH} / \mathrm{g}$ oil (Table 4). These values are lower than the maximum value allowed for refined vegetable oils ( $0.6 \mathrm{mg} \mathrm{KOH} / \mathrm{g}$ oil) [3]. The statistical analysis of the results showed that there are no significant effects of treatment conditions on the acidity of supplemented oils. In addition, no significant differences between supplemented and non-supplemented oil samples were found. This means that extraction time and the amount of algae did not affect the acidity of the sunflower oil. 
Table 4. CCRD results for acid value, oxidation products, and sensory analysis for each sample of supplemented sunflower oil. Sample 13 is the original refined sunflower oil submitted to a $20 \mathrm{~min}$ ultrasound treatment (average values and standard deviations, STD, of three replicates).

\begin{tabular}{|c|c|c|c|c|c|c|c|c|c|c|c|}
\hline \multirow[t]{2}{*}{ Assay } & \multicolumn{2}{|c|}{$\begin{array}{c}\text { Acid Value } \\
\text { (mg KOH/g Oil) }\end{array}$} & \multicolumn{6}{|c|}{ Oxidation Products } & \multicolumn{3}{|c|}{ Sensory Analysis } \\
\hline & & STD & $\mathbf{K}_{232}$ & STD & $\mathrm{K}_{270}$ & STD & $\Delta \mathrm{K}$ & STD & Average & STD & Median \\
\hline 1 & 0.12 & $0.02 \times 10^{-1}$ & 3.16 & 0.16 & 1.21 & 0.06 & 0.12 & 0.02 & 1.3 & 0.5 & 1.0 \\
\hline 2 & 0.12 & $0.01 \times 10^{-1}$ & 3.25 & 0.16 & 1.26 & 0.06 & 0.16 & 0.01 & 2.1 & 0.9 & 2.0 \\
\hline 3 & 0.12 & $0.01 \times 10^{-1}$ & 3.24 & 0.16 & 1.25 & 0.06 & 0.16 & 0.02 & 2.2 & 0.9 & 2.0 \\
\hline 4 & 0.12 & $0.03 \times 10^{-2}$ & 3.24 & 0.16 & 1.21 & 0.06 & 0.13 & 0.01 & 2.1 & 1.5 & 2.0 \\
\hline 5 & 0.12 & $0.01 \times 10^{-1}$ & 3.17 & 0.16 & 1.21 & 0.06 & 0.10 & 0.01 & 1.8 & 1.2 & 1.5 \\
\hline 6 & 0.12 & $0.03 \times 10^{-1}$ & 3.25 & 0.16 & 1.21 & 0.06 & 0.13 & 0.02 & 3.3 & 1.4 & 3.0 \\
\hline 7 & 0.16 & 0.04 & 3.33 & 0.17 & 1.26 & 0.06 & 0.17 & 0.02 & 1.6 & 0.5 & 2.0 \\
\hline 8 & 0.08 & 0.04 & 3.30 & 0.16 & 1.24 & 0.06 & 0.15 & 0.01 & 3.0 & 1.5 & 3.0 \\
\hline 9 & 0.12 & $0.01 \times 10^{-1}$ & 3.33 & 0.17 & 1.27 & 0.06 & 0.15 & 0.02 & 2.3 & 1.4 & 2.0 \\
\hline 10 & 0.12 & $0.05 \times 10^{-1}$ & 3.28 & 0.16 & 1.21 & 0.06 & 0.13 & 0.01 & 2.8 & 1.6 & 3.0 \\
\hline 11 & 0.12 & $0.02 \times 10^{-1}$ & 3.24 & 0.16 & 1.22 & 0.06 & 0.14 & 0.02 & 2.8 & 1.0 & 2.0 \\
\hline 12 & 0.12 & $0.03 \times 10^{-1}$ & 3.42 & 0.17 & 1.31 & 0.07 & 0.32 & 0.02 & 2.2 & 1.1 & 2.0 \\
\hline 13 & 0.12 & $0.02 \times 10^{-2}$ & 3.18 & 0.16 & 1.28 & 0.06 & 0.10 & 0.01 & - & & - \\
\hline
\end{tabular}

\subsubsection{Oxidation Products}

The oxidation state of the oils was evaluated by absorbance measurements at 232 and $270 \mathrm{~nm}, \mathrm{~K}_{232}$ and $\mathrm{K}_{270}$. Primary oxidation products (conjugated dienes, namely conjugated hydroperoxides) absorb at $232 \mathrm{~nm}$, while secondary oxidation products (e.g., unsaturated ketones, short-chain fatty acids, and aldehydes) absorb at $270 \mathrm{~nm}$. However, conjugated trienes formed during oil refining, in the bleaching process by active earths, also absorb at $270 \mathrm{~nm}$. Thus, in principle, $\mathrm{K}_{270}$ should not be applicable to refined oils [50]. In fact, there are no legal limits for $\mathrm{K}_{232}$ and $\mathrm{K}_{270}$ for refined oils. However, in this study, $\mathrm{K}_{232}$ and $\mathrm{K}_{270}$ values were used to assess the oxidation state of the samples after ultrasound treatment since all the values were compared to those of the original sunflower refined oil.

The statistical analysis of the results showed that there were no significant effects of treatment conditions on the oxidation of supplemented oil samples. This means that the extraction time and algae concentration had no impact on oil oxidation.

\subsubsection{Sensory Analysis}

Consumer perception and acceptance of a food are particularly based on its sensory properties. All samples of supplemented oil presented sensory defects, described as the smell of algae/fish/rotten fish, with average sensory scores between 1.3 and 3.3 and median values between 1 (very slight intensity) and 3 (medium intensity) in a discontinuous scale from 1 to 5 (Table 4). The intensity of defects showed to slightly increase with the ultrasound-assisted extraction time. However, the statistical analysis of the results showed that neither algae concentration nor UAE time had any significant effects on the intensity of sensory off-flavors in the supplemented samples. It seems that the volatile compounds are transferred from the algae to the oil very rapidly. The lack of relationship between the algae concentration and the sensory defects may be ascribed to the low solubility of these volatiles in the oil.

\subsection{Chlorophyll Pigments and Carotenoids Contents in Supplemented Sunflower Oil}

Table 5 shows the amount of chlorophyll pigments and carotenoids present in supplemented sunflower oil samples, as well as the extraction yield $(Y)$ for each group of compounds extracted from the algae to the oil during UAE. Extraction yields were calculated as follows:

$$
Y=\frac{\left[C_{s o}-C_{o}\right]}{C_{\text {algae }}} \times 100
$$


where $C_{s o}$ is the concentration of the compound in the supplemented oil, $C_{o}$ is the initial concentration of that compound in the original oil submitted to $20 \mathrm{~min}$ ultrasounds, and $C_{\text {algae }}$ is the amount of that compound available from the algae in contact with the oil.

Table 5. CCRD results for the concentration of chlorophyll pigments and carotenoids for each sample of supplemented sunflower oil. Sample 13 is the original refined sunflower oil with a 20 min ultrasound treatment; (average values and standard deviations, STD, of three replicates).

\begin{tabular}{|c|c|c|c|c|c|c|}
\hline \multirow[b]{2}{*}{ Assay } & \multicolumn{3}{|c|}{ Chlorophyll Pigments } & \multicolumn{3}{|c|}{ Carotenoids } \\
\hline & $\begin{array}{c}\text { (mg } \\
\text { Pheophytin a/kg Oil) }\end{array}$ & STD & $\begin{array}{l}\text { Extraction } \\
\text { Yield (\%) }\end{array}$ & $\begin{array}{c}\text { [ } \beta \text {-Carotene] } \\
\text { (mg/kg Oil) }\end{array}$ & STD & $\begin{array}{l}\text { Extraction } \\
\text { Yield (\%) }\end{array}$ \\
\hline 1 & 37.15 & 1.86 & 78.00 & 4.87 & 0.04 & 20.20 \\
\hline 2 & 37.90 & 1.89 & 79.56 & 6.34 & 0.03 & 28.08 \\
\hline 3 & 72.11 & 3.61 & 61.24 & 7.93 & 0.03 & 14.81 \\
\hline 4 & 61.70 & 3.08 & 52.40 & 8.20 & 0.04 & 15.39 \\
\hline 5 & 25.84 & 1.29 & 78.05 & 3.87 & 0.06 & 21.39 \\
\hline 6 & 66.15 & 3.31 & 50.01 & 6.45 & 0.06 & 10.32 \\
\hline 7 & 66.75 & 3.34 & 80.72 & 8.23 & 0.06 & 21.99 \\
\hline 8 & 52.27 & 2.61 & 63.21 & 6.55 & 0.03 & 16.84 \\
\hline 9 & 56.27 & 2.81 & 68.04 & 5.86 & 0.04 & 14.70 \\
\hline 10 & 53.17 & 2.66 & 64.30 & 5.90 & 0.05 & 14.80 \\
\hline 11 & 57.26 & 2.86 & 69.24 & 6.46 & 0.04 & 16.55 \\
\hline 12 & 63.34 & 3.17 & 76.60 & 5.08 & 0.05 & 12.29 \\
\hline 13 & 0.22 & 0.01 & - & 1.10 & 0.03 & - \\
\hline
\end{tabular}

\subsubsection{Chlorophyll Pigments}

The presence of chlorophyll pigments in P. canaliculata $(602 \mathrm{mg}$ pheophytin a/ $\mathrm{kg}$ of Pelvetia) suggests that the addition of the algae to the oil will cause an increase in their content in the oil (Table 5). The final content of chlorophylls in the supplemented oils varied from 25.84 to $72.11 \mathrm{mg}$ pheophytin a/ $\mathrm{kg}$ oil. These values represent $54.7 \%$ to $88.4 \%$ of the green pigments of the algae that were extracted from the oil during the UAE.

The statistical analysis of the results showed that the content of chlorophyll pigments increased linearly with algae concentration $(p=0.00002)$ and decreased with ultrasoundassisted treatment time $(p=0.021)$. In addition, a significant quadratic negative effect of algae concentration $(p=0.005)$ was observed, showing that the extraction of chlorophyll pigments from Pelvetia to the oil can be described by a convex surface as a function of algae content. No significant effects of the quadratic effect of time $(p=0.54)$ and of the interaction of the two factors $(p=0.15)$ were found regarding chlorophyll extraction to the oil. Therefore, the amount of chlorophylls in the oil can be fitted to the response surface shown in Figure 1a and described by the following second-order polynomial equation:

$$
\text { [pheophytin a] }(\mathrm{mg} / \mathrm{kg} \text { oil })=-0.775+8.128 \times[\text { algae }]-0.216 \times[\text { algae }]^{2}-0.711 t
$$

where [algae] is the concentration of the algae (d.w.), expressed in $\%(m / v)$, and $t$ corresponds to ultrasound extraction time (min). This model shows a remarkable high fit to the experimental points with a determination coefficient $R^{2}$ equal to 0.951 and an adjusted determination coefficient $\left(R^{2}\right.$ Adj $)$ of 0.932 . 


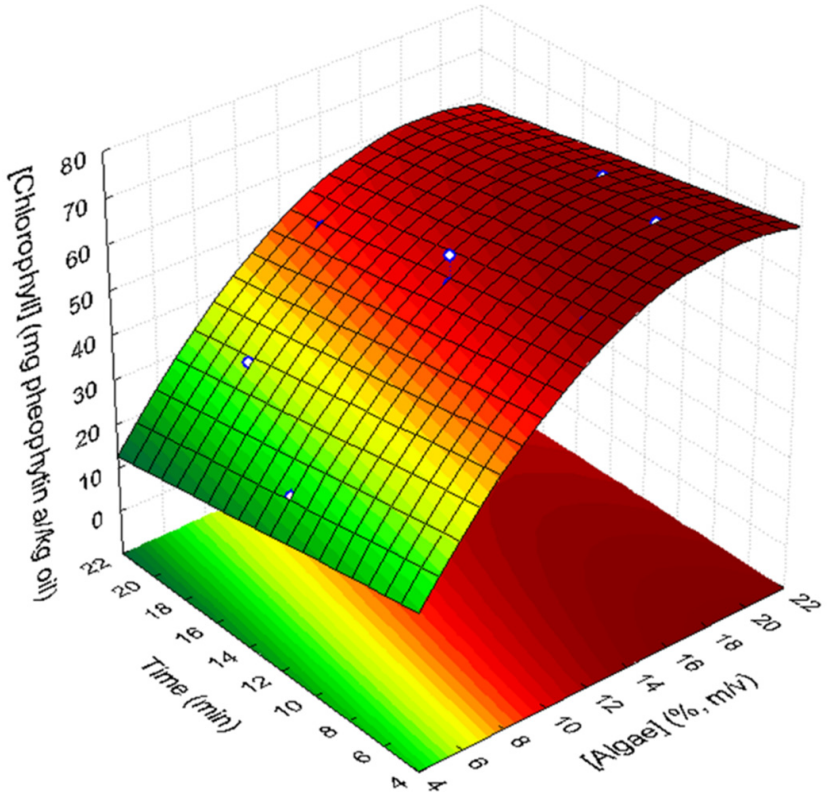

(a)

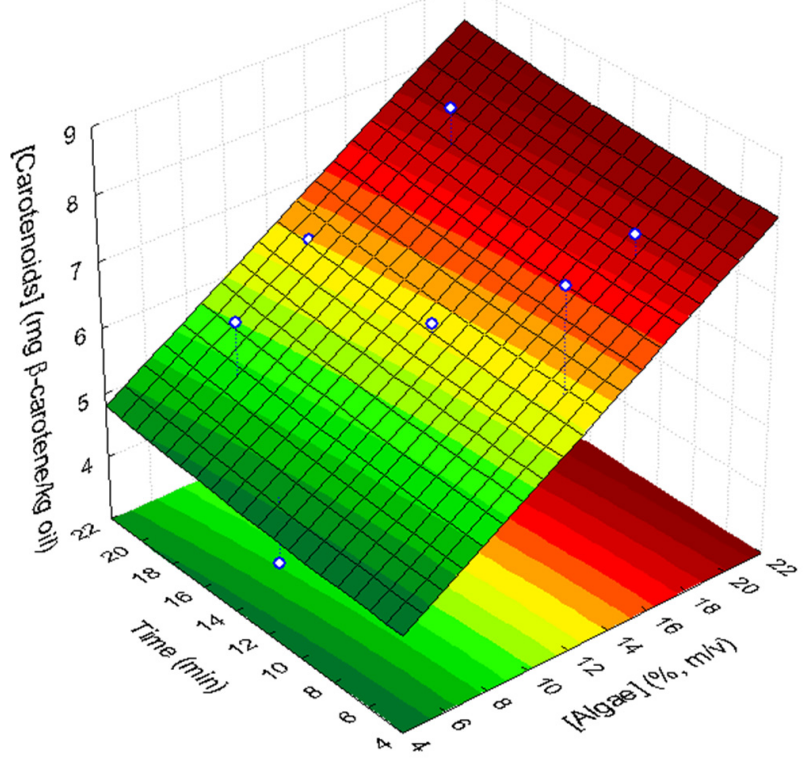

(b)

Figure 1. Response surfaces describing the effect of algae concentration and UAE time on (a) chlorophyll pigments (expressed in $\mathrm{mg}$ of pheophytin a/ $\mathrm{kg}$ oil) and (b) carotenoids ( $\mathrm{mg} \beta$-carotene/ $\mathrm{kg}$ oil) concentration in supplemented sunflower oil samples.

\subsubsection{Carotenoids}

Carotenoids appear naturally in oils. However, most of them are lost during the bleaching operation in oil refining. Table 5 shows the final amounts of carotenoids in the supplemented oils, expressed in $\beta$-carotene, with values varying from 3.87 to $8.23 \mathrm{mg} / \mathrm{kg}$ oil. Only $10.32 \%$ to $28.08 \%$ of the algal carotenoids migrated to the oils. Statistical analysis of the results showed that carotenoid ultrasound-assisted extraction from the algae to the oil linearly increased with algae concentration $(p=0.009)$. Moreover, extraction time had a significant quadratic positive effect $(p=0.028)$ on carotenoids extraction. No significant contribution of quadratic effect of algae concentration, linear effect of time, or the interaction (UAE time $x$ algae concentration) was found. Algae concentration showed a stronger impact on the amount of carotenoids extracted to the oil as compared to ultrasound extraction time. Therefore, the experimental results could be fitted to the response surface in Figure $1 \mathrm{~b}$ $\left(R^{2}=0.771 ; R^{2}\right.$ Adj $\left.=0.720\right)$ described by Equation (5):

$$
[\beta-\operatorname{carotene}](\mathrm{mg} / \mathrm{kg} \text { oil })=3.669+0.202 \times[\text { algae }]+0.0007 t^{2}
$$

where [algae] is the concentration of the algae (d.w.), expressed in $\%(m / v)$, and $t$ corresponds to ultrasound extraction time ( $\mathrm{min})$.

These results are similar to those obtained by Goula et al. [27] in UAE from pomegranate wastes to sunflower oil. They found that the increase in the ratio of pomegranate waste: sunflower oil increased the carotenoid content in the supplemented oil. Goula et al. [27] also observed that an increase in the ultrasound extraction time, from 10 to $30 \mathrm{~min}$, caused an increase in the amount of carotenoids extracted from pomegranate wastes into the vegetable oils.

\subsection{Color Evaluation}

The color is a sensory parameter that depends on the presence and amount of pigments, such as chlorophylls, carotenoids, flavonoids, and anthocyanins. This parameter can strongly influence the acceptance of a product by the consumer. In this context, the color of the samples of supplemented sunflower oil was determined and compared to 
the color of non-supplemented sunflower oil. Results regarding color evaluation by the chromatic characteristics are shown in Supplementary Materials (Table S1). The dominant wavelength of supplemented samples was constant and equal to $577 \mathrm{~nm}$, which shows to be independent of the algae concentration or the UAE time used in each experiment. Color purity of supplemented samples could be described by a second-order polynomial as a function of both UAE time and algae concentration (Figure S1). Moreover, color purity showed to increase with chlorophyll and carotenoid contents in the supplemented oils, following logarithmic models (Figure S2). All supplemented samples showed a yellow/green color, as a result of pigment extraction from the algae to the refined colorless sunflower oil. The color of supplemented oils can be perceived as a positive attribute. As an example, Figure 2 shows the color of the original oil and the color of the supplemented oil sample obtained by 20 min UAE using $12.5 \% \mathrm{~m} / v$ Pelvetia.

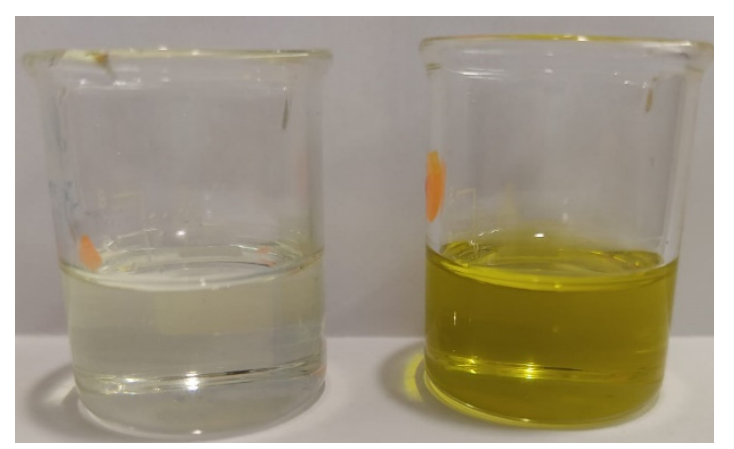

Figure 2. Non-supplemented sunflower oil (left) and supplemented sunflower oil $(12.5 \% \mathrm{~m} / \mathrm{v}$ Pelvetia; 20 min UAE) (right).

\subsection{Phenolic Compounds and Antioxidant Activity \\ 3.5.1. Phenolic Compounds}

The content of total phenolic compounds in supplemented sunflower oil samples, as well as the extraction yield, are presented in Table 6. Pelvetia methanolic extract had $5544 \mathrm{mg}$ equivalent of gallic acid $/ \mathrm{kg}$ lyophilized alga. So, it was expected that the addition of this alga to the oil would increase the phenolic content. In fact, all the supplemented oil samples presented higher phenolic contents (8.68 to 26.41 equivalent $\mathrm{mg}$ of gallic acid $/ \mathrm{kg}$ oil) than the original refined sunflower oil (0.4 equivalent $\mathrm{mg}$ of gallic acid $/ \mathrm{kg}$ oil). However, the extraction yields from the algae to the oils were rather low, ranging from $0.92 \%$ to $3.10 \%$ (Table 6). This may be explained by the low solubility of the phenolic compounds of Pelvetia in the oil.

The statistical analysis of the CCRD results showed that algae concentration and UAE time had a significant negative linear effect ( $p=0.0015$ and $p=0.001$, respectively) on phenolic extraction from algae to the oil. On the other hand, the interaction of these two factors (algae concentration $\times$ time) had a significant positive linear effect $(p=0.005)$ on the extraction of these compounds to the oil. The quadratic positive effects of extraction time $(p=0.011)$ and Pelvetia concentration indicate that the phenolic content of supplemented samples can be fitted to a concave response surface (Figure $3 \mathrm{a}$ ) as a function of both factors, described by the following second-order polynomial equation $\left(R^{2}=0.961 ; R^{2}\right.$ Adj $\left.=0.922\right)$ :

$$
\begin{aligned}
{[\text { gallic acid }](\mathrm{mg} / \text { kgoil })=} & 36.02-1.98[\text { algae }]+0.04[\text { algae }]^{2}-3.51 t+ \\
& 0.10 t^{2}+0.14[\text { algae }] t
\end{aligned}
$$

where [algae] is the concentration of the algae, expressed in $\%(\mathrm{~m} / \mathrm{v})$, and $t$ corresponds to ultrasound extraction time ( $\mathrm{min})$. 
Table 6. CCRD results for the concentration of total phenolic compounds and flavonoids of each sample of supplemented sunflower oil. Sample 13 is the original refined sunflower oil with a 20 min ultrasound treatment (average values and standard deviations, STD, of three replicates; ${ }^{*}$ the phenolic compounds of sample 9 , corresponding to one repetition of the central point, could not be determined due to sample shortage).

\begin{tabular}{cccccccccc}
\hline & \multicolumn{3}{c}{ Phenolic Content } & \multicolumn{5}{c}{ Flavonoids } \\
\cline { 2 - 10 } Assay & $\begin{array}{c}\text { [Gallic Acid] } \\
\text { (mg/kg Oil) }\end{array}$ & STD & $\begin{array}{c}\text { Extraction } \\
\text { Yield (\%) }\end{array}$ & $\begin{array}{c}\text { [Quercetin] } \\
\text { (mg/kg Oil) }\end{array}$ & STD & $\begin{array}{c}\text { Extraction } \\
\text { Yield (\%) }\end{array}$ & $\begin{array}{c}\text { [Catechin] } \\
\text { (mg/kg Oil) }\end{array}$ & $\begin{array}{c}\text { STD } \\
\text { Extraction } \\
\text { Yield (\%) }\end{array}$ \\
\hline 1 & 10.26 & 0.51 & 2.47 & 84.23 & 4.21 & 4.60 & 31.76 & 1.59 \\
2 & 11.09 & 0.55 & 2.68 & 110.69 & 5.53 & 9.28 & 41.89 & 2.09 & 9.65 \\
3 & 9.47 & 0.47 & 0.92 & 94.24 & 4.71 & 2.58 & 35.59 & 1.78 & 2.61 \\
4 & 26.41 & 1.32 & 2.64 & 97.77 & 4.89 & 2.83 & 36.95 & 1.85 & 2.86 \\
5 & 7.79 & 0.39 & 2.67 & 73.24 & 3.66 & 3.82 & 27.56 & 1.38 & $3 ., 87$ \\
6 & 18.71 & 0.94 & 1.65 & 93.57 & 4.68 & 2.25 & 35.34 & 1.77 & 2.28 \\
7 & 11.67 & 0.58 & 1.63 & 85.01 & 4.25 & 2.73 & 32.07 & 1.60 & 2.76 \\
8 & 21.91 & 1.10 & 3.10 & 77.25 & 3.86 & 1.94 & 29.09 & 1.45 & 1.96 \\
9 & $*$ & - & $*$ & $*$ & - & $*$ & $*$ & $*$ \\
10 & 10.45 & 0.52 & 1.45 & 90.9 & 4.55 & 3.33 & 34.32 & 1.72 & 3.37 \\
11 & 8.68 & 0.43 & 1.19 & 84.20 & 4.21 & 2.64 & 31.76 & 1.63 & 2.68 \\
12 & 13.49 & 0.67 & 1.89 & 66.58 & 3.33 & 0.85 & 25.01 & 1.25 & 0.86 \\
13 & 0.40 & 0.02 & - & 58.26 & 2.91 & - & 21.83 & 1.09. \\
\hline
\end{tabular}

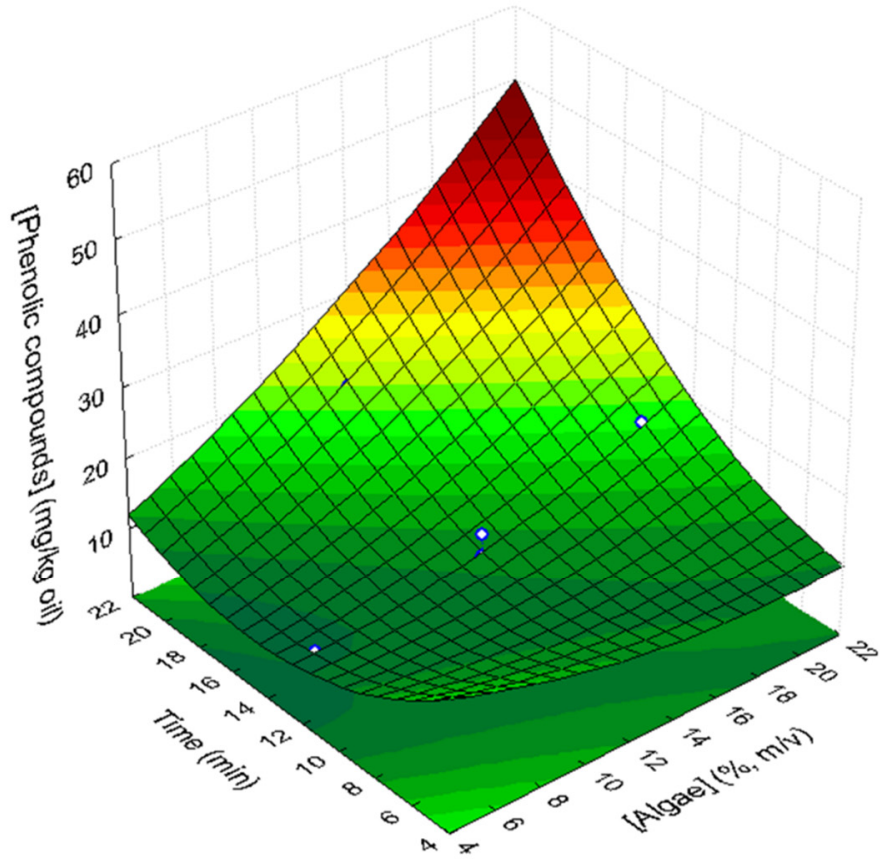

(a)

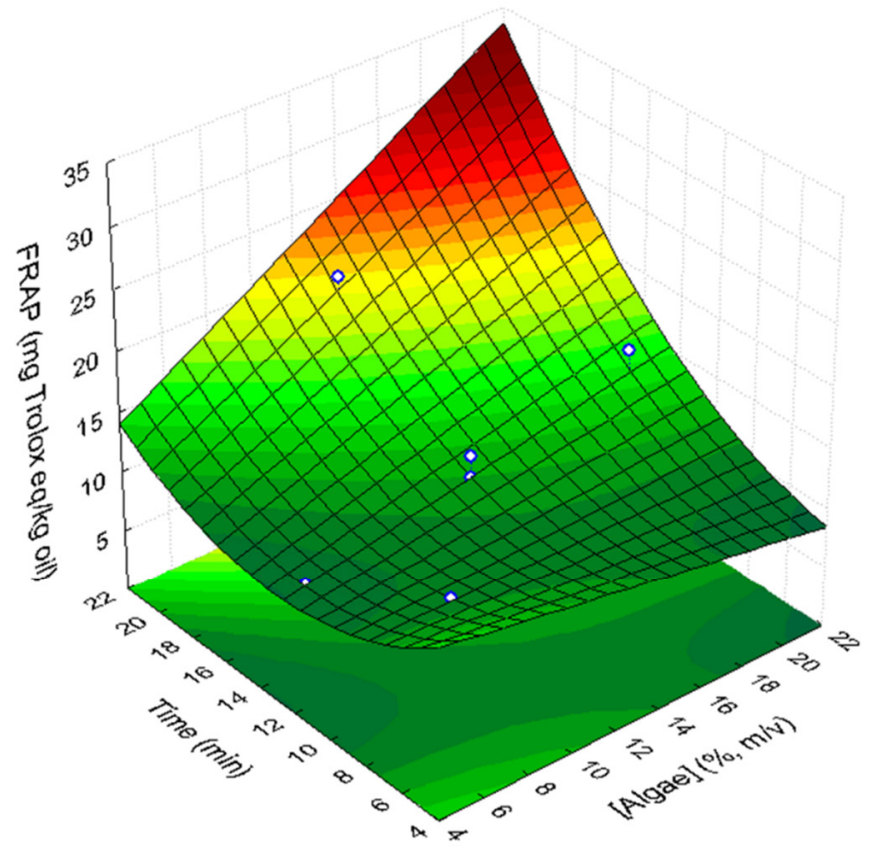

(b)

Figure 3. Response surfaces describing the effect of algae concentration and UAE time on (a) phenolic compounds concentration, expressed in equivalent $\mathrm{mg}$ of gallic acid/ $\mathrm{kg}$ oil, and (b) antioxidant activity evaluated by the FRAP method in supplemented sunflower oil samples.

Jiménez-Escrig et al. [51] evaluated the phenolic content of aqueous and organic extracts of brown and red algae, and they concluded that acetone:water solution $(70: 30, v / v)$ was more efficient in the extraction of phenolic compounds. In our study, the highest amount extracted corresponds to $3.1 \%$ of the phenolic compounds from the algae. Conversely, López et al. [52], who determined the phenolic content of different extracts of the brown alga Stypocaulon scoparium, concluded that the aqueous extract had the highest phenolic content. 


\subsubsection{Flavonoids}

In this study, the flavonoid content in the algae and supplemented sunflower oil samples was determined and expressed as equivalent of catechin and equivalent of quercetin per kg of oil (Table 6). Quercetin and catechin are the flavonoids that are the most widely distributed in edible plants. Moreover, several authors, such as Saad et al. [53], refer to the presence of catechin and quercetin in algae (Red Marine Alga Alsidium corallinum). In this work, the authors expressed flavonoids using more than one standard to make a comparison to other authors easier, as several are used in the literature (including rutin, beyond quercetin and catechin).

The algae present $2966 \mathrm{mg}$ of catechin or $7849 \mathrm{mg}$ of quercetin $/ \mathrm{kg}$ lyophilized algae. Therefore, it was expected that supplemented oil had much more flavonoids than nonsupplemented oil. However, the results presented in Table 6 show a limited extraction of flavonoids to the oil, with extraction yields varying from $0.85 \%$ to around $9.40 \%$. These results can be explained by the low solubility of flavonoids of Pelvetia in the oil. Moreover, when the statistical analysis was performed on the CCRD results, no significant effects of algae concentration or UAE time on flavonoids extraction were observed.

Our results are in contrast with those obtained by Murugan and Iyer [54] and by Chan et al. [9]. Murugan and Iyer [54] determined the flavonoid content of methanol, chloroform, ethyl acetate, and aqueous extracts of the brown alga Turbinaria ornata and detected the highest flavonoid content $(88.4 \mu \mathrm{g}$ catechin equivalent $/ \mathrm{mL}$ extract) in the chloroform extract, which was the less polar solvent tested. Chan et al. [9] quantified the flavonoid content of various Gracilaria changii extracts and concluded that the decrease in solvent polarity promoted higher flavonoid contents in the extracts. These results indicate that the flavonoids present in Turbinaria ornata and G. changii are mainly non-polar. The difference between our results and the results obtained by other authors may be explained by the fact that the solubility of flavonoids is affected by the nature of the solvent and the flavonoid structure [55]. Thus, we may conclude that the flavonoids present in P. canaliculata are mainly nonsoluble in oil.

\subsubsection{Antioxidant Activity DPPH Assay}

The results from the radical scavenging activity of the supplemented oil samples are shown in Table 7. Methanolic extract of Pelvetia, in a concentration of $6.28 \% \mathrm{~m} / \mathrm{v}$, has $86 \%$ of RSA and 895 equivalents of $\mathrm{mg}$ Trolox/ kg lyophilized algae (Table 3). Therefore, as expected, the addition of the algae to the oil increased its radical scavenging activity. Nevertheless, the application of response surface methodology showed that there were no significant effects of algae concentration and/or ultrasound-assisted extraction time on radical scavenging activity of the supplemented oils.

Chan et al. [9] found a correlation between the DPPH radical scavenging activity and phenolic and flavonoid contents of various G. changii extracts. However, no relationship between phenolic or flavonoid contents and radical scavenging activity was detected in our study. Similarly, Cox et al. [56], who determined the free radical scavenging activity and phenolic content of various macroalgae (brown, red, and green), concluded that there was no direct relationship between phenolic content and free radical scavenging activity of macroalgae extracts. 
Table 7. Antioxidant activity of each sample of supplemented sunflower oils obtained under the conditions dictated by the CCRD followed. Sample 13 is the original refined sunflower oil with a 20 min ultrasound treatment (average values and standard deviations, STD, of three replicates; * FRAP assays of sample 9 , corresponding to one repetition of the central point, could not be determined due to sample shortage).

\begin{tabular}{|c|c|c|c|c|c|c|}
\hline \multirow[b]{2}{*}{ Assay } & \multicolumn{4}{|c|}{$\overline{\mathrm{DPPH}}$} & \multicolumn{2}{|c|}{ FRAP } \\
\hline & $\%$ RSA & STD & $\begin{array}{c}\text { Eq. Trolox } \\
\text { (mg/kg Oil) }\end{array}$ & STD & $\begin{array}{c}\text { Eq. Trolox } \\
\text { (mg/kg Oil) }\end{array}$ & STD \\
\hline 1 & 63.8 & 3.2 & 12.34 & 0.62 & 11.85 & 0.59 \\
\hline 2 & 47.4 & 2.4 & 8.96 & 0.45 & 12.36 & 0.62 \\
\hline 3 & 49.8 & 2.5 & 9.59 & 0.48 & 9.86 & 0.49 \\
\hline 4 & 60.0 & 3.0 & 11.50 & 0.58 & 19.15 & 0.96 \\
\hline 5 & 48.7 & 2.4 & 9.33 & 0.47 & 9.35 & 0.47 \\
\hline 6 & 74.4 & 3.7 & 14.47 & 0.72 & 16.58 & 0.83 \\
\hline 7 & 57.6 & 2.9 & 10.95 & 0.55 & 10.40 & 0.52 \\
\hline 8 & 77.5 & 3.9 & 14.99 & 0.75 & 21.44 & 1.07 \\
\hline 9 & 51.7 & 2.6 & 9.92 & 0.50 & * & - \\
\hline 10 & 51.1 & 2.6 & 9.78 & 0.49 & 8.91 & 0.45 \\
\hline 11 & 49.5 & 2.5 & 9.41 & 0.47 & 11.99 & 0.60 \\
\hline 12 & 55.0 & 2.8 & 10.60 & 0.53 & 13.74 & 0.69 \\
\hline 13 & 7.5 & 0.3 & 1.10 & 0.06 & 3.61 & 0.18 \\
\hline
\end{tabular}

FRAP Assays

The results of FRAP assays of the initial and supplemented oil samples are also presented in Table 7. Methanolic extract of $P$. canaliculata had $3592 \mathrm{mg} \pm 180$ Trolox $/ \mathrm{kg}$ algae (Table 3). Therefore, if the compounds responsible for antioxidant activity were liposoluble, an increase in the antioxidant activity of supplemented oils was expected. In fact, the samples of supplemented sunflower oil have higher antioxidant activity than the non-supplemented oil (Table 7). These results indicate that the compounds with antioxidant activity that migrated from the algae to the oil are mainly non-polar. Similarly, Chan et al. [9] studied the antioxidant activity, by the FRAP assay, of several G. changii extracts, using different solvents. They observed that the decrease in solvent polarity corresponded to an increase in the antioxidant activity of the extracts, which means that compounds that were responsible for antioxidant activity were mainly non-polar.

Statistical analysis of the obtained results showed that algae concentration and ultrasound extraction time have significant linear negative effects $(p=0.05$ and $p=0.008$, respectively) on the antioxidant activity of the samples. Ultrasound extraction time had a higher impact on the antioxidant activity of the compounds extracted to the oil than algae concentration. The quadratic positive effect of time and the linear interaction between the two factors are important enough to be considered in the response surface model.

Therefore, a response surface (Figure $3 b$ ), described by the following equation, was fitted to the experimental results $\left(R^{2}=0.863 ; R^{2}\right.$ Adj $\left.=0.771\right)$ :

$$
[\text { Trolox }](\mathrm{mg} / \mathrm{kg} \text { oil })=22.119-0.623[\text { algae }]-1.958 t+0.063 t^{2}+0.078[\text { algae }] t
$$

where [algae] is the concentration of the algae (d.w.), expressed in \% $(m / v)$, and $t$ corresponds to ultrasound extraction time ( $\mathrm{min})$.

Figure 3 shows that response surfaces fitted to phenolic content and to the antioxidant activity assayed by the FRAP method have a similar shape. In fact, a linear relationship, with a determination coefficient of 0.913 , was found between these two parameters (Trolox $=0.648$ [Phenols $]+4.409)$.

Chan et al. [9] also found a correlation between the phenolic content of the extracts and the antioxidant activity. However, they also found a relationship between flavonoid content and antioxidant activity and between radical scavenging activity and antioxidant activity, which was not observed in this study. 
Our results showed that the antioxidant activity of the supplemented oils, associated with the presence of phenolic compounds, is not derived from radical elimination by hydrogen donation. Thus, the antioxidant activity of supplemented sunflower oil might be explained by other mechanisms, such as: (i) capture of species that initiate peroxidation; (ii) chelation of metal ions, preventing them from generating reactive species and decomposing lipid peroxides; (iii) chelation of singlet oxygen, preventing the formation of peroxides; or (iv) reduction in local oxygen concentrations [57-59].

Data from the literature are controversial about the relationship between phenolic content and antioxidant activity because the antioxidant activity depends on the structure of phenolic compounds, their polymerization degree, and on the solvents used for extraction of active compounds $[51,52,60]$.

\subsection{Accelerated Oxidation Test}

From CCRD results, the oil sample with the highest phenolic content and antioxidant activity (DPPH and FRAP values) was obtained using $12.5 \%(\mathrm{~m} / \mathrm{v})$ of Pelvetia and submitted to 20 min UAE (Tables 6 and 7; experiment 8). For the accelerated oxidation assay, a different batch of $P$. canaliculata was used to prepare supplemented oils under the same conditions as experiment 8 .

Samples were stored in the dark at $60^{\circ} \mathrm{C}$ for 12 days. The assessment of oxidative stability was performed by DPPH and FRAP assays on the samples along the experiment (Figure 4). Concerning radical scavenging activity, the initial sample used in this experiment had $46.05 \mathrm{mg} \pm 2.30$ of Trolox $/ \mathrm{kg}$ of oil while the sample $\mathrm{n}^{\circ} 8$ from CCRD (Table 7), from a different Pelvetia batch, had $14.99 \mathrm{mg} \pm 1.20$ Trolox $/ \mathrm{kg}$ of oil. The natural variability in Pelvetia canaliculata might be the cause of different results.

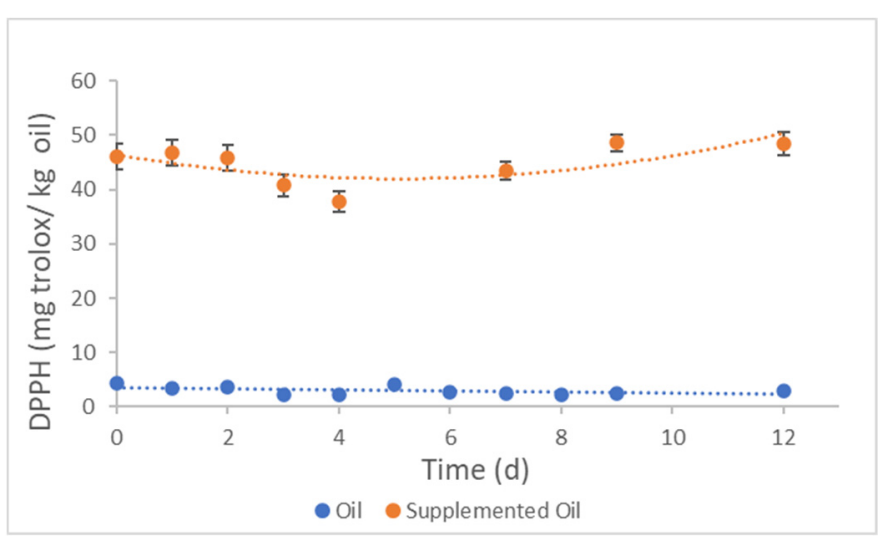

(a)

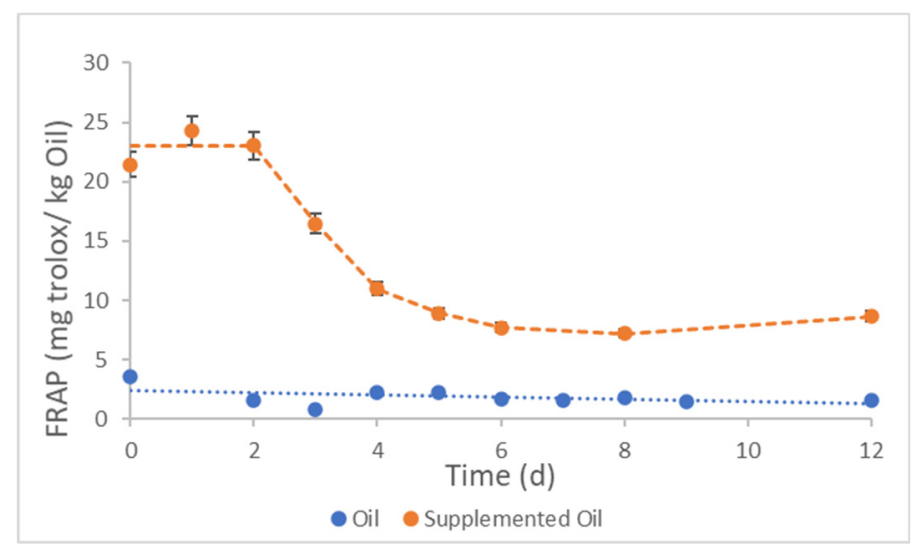

(b)

Figure 4. Accelerated oxidation tests carried out under dark at $60^{\circ} \mathrm{C}$, for 12 days, of non-supplemented and supplemented sunflower oil obtained by UAE with Pelvetia $(12.5 \%, \mathrm{~m} / \mathrm{v})$ for $20 \mathrm{~min}$. The antioxidant activity was assayed by $(\mathbf{a}) \mathrm{DPPH}$ and (b) FRAP methods.

The supplemented sunflower oil had 10 times higher radical scavenging activity than the non-supplemented sample ( $4.42 \mathrm{mg} \pm 0.22$ of Trolox $/ \mathrm{kg}$ of oil). Along the experiment, radical scavenging activity of supplemented and non-supplemented oils remained constant, with small oscillations (Figure 4a). After 12 days at $60^{\circ} \mathrm{C}$, the radical scavenging activity of supplemented sunflower oil was $48.51 \mathrm{mg} \pm 2.43$ of Trolox $/ \mathrm{kg}$ of oil, while in the non-supplemented sample, it decreased to $2.97 \mathrm{mg} \pm 0.15$ of Trolox $/ \mathrm{kg}$ of oil. These results indicate that Pelvetia improved radical scavenging activity and, consequently, increased the oxidative stability of sunflower oil.

However, our results are not in accordance with the ones obtained by other authors. Yang et al. [61] studied the radical scavenging activity of soybean, rice, and cotton oils, kept at $62{ }^{\circ} \mathrm{C}$ for 24 days. Siraj et al. [62] studied the radical scavenging activity of canola and sunflower oils supplemented with pomegranate seed oil, kept at $62{ }^{\circ} \mathrm{C}$ for 60 days. In both 
studies, the authors observed a decrease in radical scavenging activity during the storage. This might indicate that the DPPH test is not adequate to follow the oxidative stability of sunflower oil supplemented with Pelvetia extracts under accelerated storage conditions.

Therefore, the antioxidant activity of the samples was also determined by the FRAP test (Figure $4 \mathrm{~b}$ ). On day 0 , the supplemented sunflower oil had an antioxidant activity of $21.4 \mathrm{mg} \pm 1.1$ of Trolox $/ \mathrm{kg}$ that remained almost constant during $48 \mathrm{~h}$ under heated storage conditions. Then, the antioxidant activity of the supplemented sunflower oil decreased with storage time and reached $8.6 \mathrm{mg} \pm 0.4$ of Trolox $/ \mathrm{kg}$ of oil after 12 days. With respect to the non-supplemented oil, its initial antioxidant activity of $3.6 \mathrm{mg} \pm 0.2$ of Trolox $/ \mathrm{kg}$ of oil linearly decreased to $1.6 \mathrm{mg} \pm 0.1 \mathrm{of}$ Trolox $/ \mathrm{kg}$ of oil along 12 days at $60^{\circ} \mathrm{C}$. These results indicate that the supplementation of sunflower oil with Pelvetia extracts significantly improved its antioxidant activity. Our results are in accordance with Tinello et al. [63], who observed a decrease in the antioxidant activity of soybean oil enriched with turmeric and ginger over storage time $\left(62{ }^{\circ} \mathrm{C} / 28\right.$ days). In conclusion, FRAP seems to be a more accurate test than DPPH to follow the oxidative stability of sunflower oil supplemented with Pelvetia extracts and submitted to accelerated storage conditions $\left(60^{\circ} \mathrm{C}\right)$.

\section{Conclusions}

In this study, bioactive compounds were successfully extracted from the lyophilized alga Pelvetia canaliculata directly to the sunflower oil, using non-pollutant ultrasoundassisted extraction. The optimization of UAE conditions was performed by response surface methodology following a central composite rotatable design as a function of algae concentration and ultrasound-assisted extraction time. The extraction of compounds from Pelvetia did not affect the chemical quality parameters of the supplemented oils. Both chlorophyll and carotenoid contents increased after the supplementation, giving a yellow/green color to the oils. However, the addition of Pelvetia induced odor defects in the oil, from very slight to medium intensity, which may compromise consumers' acceptability. Therefore, it would be necessary to deodorize the supplemented oils, to remove these offflavors.

Moreover, phenolic content and antioxidant activity increased in all supplemented samples. A linear correlation between antioxidant activity variation (FRAP) and phenolic content was observed. The highest antioxidant activity was observed in the sample prepared with $12.5 \% \mathrm{~m} / \mathrm{v}$ of Pelvetia and $20 \mathrm{~min}$ of UAE. Therefore, this sample was subjected to an accelerated oxidation test, performed in the dark at $60^{\circ} \mathrm{C}$ for 12 days. FRAP assay showed to be the most adequate to follow the antioxidant activity of the supplemented and non-supplemented oils along accelerated oxidation test. Along this experiment, the antioxidant activity of supplemented oil was about six times the value of non-supplemented oil. Final samples showed $40 \%$ of initial antioxidant activity.

The results obtained in this study highlight the applicability of ultrasound-assisted extraction and the potential use of algae as a source of bioactive compounds in oils. This supplementation increases the oxidative stability, the biological and economical values of the sunflower oil.

Supplementary Materials: The following are available online at https:/ / www.mdpi.com/article/10 .3390 /foods10081732/s1, Figure S1: Response surface describing the effect of algae concentration and UAE time on color purity of the supplemented oil, Figure S2: Relationships between color purity of supplemented oil samples and concentration of chlorophylls and carotenoids, Table S1: CCRD results for the chromatic properties of each sample of supplemented oil, for the original sunflower oil.

Author Contributions: Conceptualization, C.T. and S.F.-D.; methodology, G.S., M.T., I.M., M.M., V.A., R.V., P.A.L., L.A., M.N., C.T., and S.F.-D.; laboratory work, G.S., M.T., and M.A.; resources, C.T.; data curation, G.S., M.T., M.N., C.T., and S.F.-D.; writing—original draft preparation, G.S. and M.T.; writing-review and editing, I.M., M.M., V.A., R.V., P.A.L., L.A., M.N., C.T., and S.F.-D.; supervision, S.F.-D.; project administration, C.T.; funding acquisition, C.T. All authors have read and agreed to the published version of the manuscript. 
Funding: This research was funded by the Research Project Ocean2Oils "Integrated approach for seaweeds application as sustainable source of functional compounds for edible oils stabilization and food processing" (FA_05_2017_013), co-funded by Fundo Azul program through the Direção-Geral de Política do Mar, Portugal.

Data Availability Statement: Data will be available on request to the authors.

Acknowledgments: The authors thank Teresa Mouga (Polytechnic of Leiria, Portugal) for the taxonomic identification of Pelvetia canaliculata L., Rita Simões (ISA, Portugal) for helping in antioxidant activity assays, the research units from Fundação para a Ciência e a Tecnologia, I.P.: LEAF (UIDP/04129/2020; UIDB/04129/2020) and MARE (UID/MAR/04292/2020), and the Erasmus Program for the grant to Marija Trifunovska.

Conflicts of Interest: The authors declare no conflict of interest.

\section{References}

1. Statista-Production of Major Vegetable Oils Worldwide from 2012/13 to 2018/2019 by Type. Vegetable Oils and Fats. Available online: https:/ / www.statista.com/statistics/263933/production-of-vegetable-oils-worldwide-since-2000/ (accessed on 17 December 2020).

2. Salas, J.J.; Bootello, M.A.; Garcés, R. Food uses of sunflower oils. In Sunflower Chemistry, Production, Processing, and Utilization, 1st ed.; Martínez-Force, E., Dunford, N., Salas, J., Eds.; Academic Press: Cambridge, MA, USA; AOCS Press: Urbana, IL, USA, 2015; pp. 441-464.

3. Alimentarius, C. Codex standard for named vegetable oils. Codex Stan 1999, 210, 1-13.

4. Grompone, M. Sunflower Oil. In Vegetable Oils in Food Technology: Composition, Properties and Uses, 2nd ed.; Gunstone, F., Ed.; John Wiley \& Sons: Hoboken, NJ, USA, 2011; pp. 137-167.

5. Pighinelli, A.L.M.T.; Park, K.J.; Rauen, A.M.; De Oliveira, R.A. Otimização da prensagem de grãos de girassol e sua caracterização. Rev. Bras. Eng. Agrícola Ambient. 2009, 13, 63-67. [CrossRef]

6. Miraliakbari, H.; Shahidi, F. Oxidative Stability of Tree Nut Oils. J. Agric. Food Chem. 2008, 56, 4751-4759. [CrossRef] [PubMed]

7. Gunstone, F.D. Oils and Fats in the Food Industry; John Wiley \& Sons: Hoboken, NJ, USA, 2008. [CrossRef]

8. Pokorný, J.; Yanishlieva, N.; Gordon, M.H. Antioxidants in Food: Practical Application; CRC Press: Boca Raton, FL, USA, 2001.

9. Chan, P.T.; Matanjun, P.; Yasir, S.M.; Tan, T.S. Antioxidant activities and polyphenolics of various solvent extracts of red seaweed, Gracilaria changii. Environ. Boil. Fishes 2014, 27, 2377-2386. [CrossRef]

10. Aladedunye, F.A. Curbing thermo-oxidative degradation of frying oils: Current knowledge and challenges. Eur. J. Lipid Sci. Technol. 2015, 117, 1867-1881. [CrossRef]

11. Taha, E.; Abouelhawa, S.; El-Geddawy, M.; Sorour, M.; Aladedunye, F.; Matthäus, B. Stabilization of refined rapeseed oil during deep-fat frying by selected herbs. Eur. J. Lipid Sci. Technol. 2014, 116, 771-779. [CrossRef]

12. Aminzare, M.; Hashemi, M.; Ansarian, E.; Bimkar, M.; Azar, H.H.; Mehrasbi, M.R.; Daneshamooz, S.; Raeisi, M.; Jannat, B.; Afshari, A. Using Natural Antioxidants in Meat and Meat Products as Preservatives: A Review. Adv. Anim. Vet. Sci. 2019, 7. [CrossRef]

13. Mezza, G.N.; Borgarello, A.V.; Grosso, N.R.; Fernandez, H.; Pramparo, M.C.; Gayol, M.F. Antioxidant activity of rosemary essential oil fractions obtained by molecular distillation and their effect on oxidative stability of sunflower oil. Food Chem. 2018, 242, 9-15. [CrossRef]

14. Sayyari, Z.; Farahmandfar, R. Stabilization of sunflower oil with pussy willow (Salix aegyptiaca) extract and essential oil. Food Sci. Nutr. 2016, 5, 266-272. [CrossRef]

15. Neves, M.; Miranda, A.; Lemos, M.F.; Silva, S.; Tecelão, C. Enhancing oxidative stability of sunflower oil by supplementation with prickled broom (Pterospartum tridentatum) ethanolic extract. J. Food Sci. 2020, 85, 2812-2821. [CrossRef]

16. Connan, S.; Deslandes, E.; Gall, E.A. Influence of day-night and tidal cycles on phenol content and antioxidant capacity in three temperate intertidal brown seaweeds. J. Exp. Mar. Biol. Ecol. 2007, 349, 359-369. [CrossRef]

17. Hackbarth, F.V.; Girardi, F.; de Souza, S.M.G.U.; de Souza, A.A.U.; Boaventura, R.A.; Vilar, V.J. Marine macroalgae Pelvetia canaliculata (Phaeophyceae) as a natural cation exchanger for cadmium and lead ions separation in aqueous solutions. Chem. Eng. J. 2014, 242, 294-305. [CrossRef]

18. Neiva, J.; Assis, J.; Fernandes, F.; Pearson, G.A.; Serrão, E.A. Species distribution models and mitochondrial DNA phylogeography suggest an extensive biogeographical shift in the high-intertidal seaweed Pelvetia canaliculata. J. Biogeogr. 2014, 41, 1137-1148. [CrossRef]

19. Valentão, P.; Trindade, P.; Gomes, D.; de Pinho, P.G.; Mouga, T.; Andrade, P.B. Codium tomentosum and Plocamium cartilagineum: Chemistry and antioxidant potential. Food Chem. 2010, 119, 1359-1368. [CrossRef]

20. Rodrigues, D.; Freitas, A.; Pereira, L.; Rocha-Santos, T.; Vasconcelos, M.W.; Roriz, M.; Rodríguez-Alcalá, L.M.; Gomes, A.M.; Duarte, A. Chemical composition of red, brown and green macroalgae from Buarcos bay in Central West Coast of Portugal. Food Chem. 2015, 183, 197-207. [CrossRef] 
21. Kirke, D.; Smyth, T.; Rai, D.; Kenny, O.; Stengel, D. The chemical and antioxidant stability of isolated low molecular weight phlorotannins. Food Chem. 2017, 221, 1104-1112. [CrossRef] [PubMed]

22. Chater, P.I.; Wilcox, M.; Cherry, P.; Herford, A.; Mustar, S.; Wheater, H.; Brownlee, I.; Seal, C.; Pearson, J. Inhibitory activity of extracts of Hebridean brown seaweeds on lipase activity. J. Appl. Phycol. 2015, 28, 1303-1313. [CrossRef] [PubMed]

23. Cherry, P.; O'Hara, C.; Magee, P.; McSorley, E.M.; Allsopp, P.J. Risks and benefits of consuming edible seaweeds. Nutr. Rev. 2019, 77, 307-329. [CrossRef] [PubMed]

24. Colliec, S.; Boisson-vidal, C.; Jozefonvicz, J. A low molecular weight fucoidan fraction from the brown seaweed Pelvetia canaliculata. Phytochemistry 1994, 35, 697-700. [CrossRef]

25. Makkar, H.P.; Tran, G.; Heuzé, V.; Giger-Reverdin, S.; Lessire, M.; Lebas, F.; Ankers, P. Seaweeds for livestock diets: A review. Anim. Feed Sci. Tech. 2016, 212, 1-17. [CrossRef]

26. Zhang, R.; Yuen, A.; Magnusson, M.; Wright, J.; de Nys, R.; Masters, A.; Maschmeyer, T. A comparative assessment of the activity and structure of phlorotannins from the brown seaweed Carpophyllum flexuosum. Algal Res. 2018, 29, 130-141. [CrossRef]

27. Goula, A.M.; Papatheodorou, A.; Karasavva, S.; Kaderides, K. Ultrasound-assisted aqueous enzymatic extraction of oil from pomegranate seeds. Waste Biomass Valorization 2016, 9, 1-11. [CrossRef]

28. Nde, D.B.; Foncha, A.C. Optimization Methods for the Extraction of Vegetable Oils: A Review. Processes 2020, 8, 209. [CrossRef]

29. Lourenço, S.O.; Barbarino, E.; De-Paula, J.C.; Pereira, L.O.D.S.; Lanfer Marquez, U.M. Amino acid composition, protein content and calculation of nitrogen-to-protein conversion factors for 19 tropical seaweeds. Phycol. Res. 2002, 50, 233-241. [CrossRef]

30. Folch, J.; Lees, M.; Stanley, G.S. A simple method for the isolation and purification of total lipids from animal tissues. J. Biol. Chem. 1957, 226, 497-509. [CrossRef]

31. Pokorný, J.; Kalinova, L.; Dysseler, P. Determination of chlorophyll pigments in crude vegetable oils: Results of a collaborative study and the standardized method (Technical Report). Pure Appl. Chem. 1995, 67, 1781-1787. [CrossRef]

32. Rougereau, A.; Person, O.; Rougereau, G. Determination of vitamins. In Analysis of Food Constituents; Multon, J.-L., Ed.; Wiley-VCH: New York, NY, USA, 1997; pp. 281-309.

33. Nawrocka, A.; Lamorska, J. Determination of food quality by using spectroscopic methods. In Advances in Agrophysical Research; Grundas, S., Stępniewski, A., Eds.; IntechOpen: London, UK, 2013; pp. 347-368. Available online: https://www.intechopen.com/ chapters/39943 (accessed on 1 December 2020).

34. Matanjun, P.; Mohamed, S.; Mustapha, N.M.; Muhammad, K.; Ming, C.H. Antioxidant activities and phenolics content of eight species of seaweeds from north Borneo. J. Appl. Phycol. 2008, 20, 367-373. [CrossRef]

35. Laulloo, S.S.J.; Bhowon, M.G.; Hoolash, A. Influence of chemical refining processes on the total phenolics and antioxidant activity of sunflower oil. Int. J. Nutr. 2015, 1, 38-47. [CrossRef]

36. Brand-Williams, W.; Cuvelier, M.; Berset, C. Use of a free radical method to evaluate antioxidant activity. LWT Food Sci. Technol. 1995, 28, 25-30. [CrossRef]

37. Benzie, I.F.; Strain, J.J. The ferric reducing ability of plasma (FRAP) as a measure of "antioxidant power": The FRAP assay. Anal. Biochem. 1996, 239, 70-76. [CrossRef]

38. Leardi, R. Experimental design in chemistry: A tutorial. Anal. Chim. Acta 2009, 652, 161-172. [CrossRef]

39. Montgomery, D.C. Design and Analysis of Experiments, 3rd ed.; John Wiley \& Sons: New York, NY, USA, $1991 ;$ pp. 521-568.

40. Commission Regulation (EEC) No. 2568/91 of 11 July 1991 on the Characteristics of Olive Oil and Olive-Residue Oil and on the Relevant Methods of Analysis, Official Journal L 248, 5 September 1991. Offic. JL, 248, 1-128. Available online: https:/ / eur-lex. europa.eu/legal-content/EN/TXT/PDF/?uri=CELEX:01991R2568-20151016\&from=EN (accessed on 1 December 2020).

41. Norma Portuguesa. NP 937 (1987) Gorduras e Óleos Comestíveis_Determinação da Cor Dos óleos e Suas Características Cromáticas. Processo Corrente; Instituto Português da Qualidade: Lisboa, Portugal, 1987; p. 11.

42. Hrncirik, K.; Fritsche, S. Comparability and reliability of different techniques for the determination of phenolic compounds in virgin olive oil. Eur. J. Lipid Sci. Technol. 2004, 106, 540-549. [CrossRef]

43. Haaland, P.D. Experimental Design in Biotechnology, 1st ed.; CRC Press: New York, NY, USA, 1989; p. 259.

44. Maehre, H.K.; Malde, M.K.; Eilertsen, K.-E.; Elvevoll, E.O. Characterization of protein, lipid and mineral contents in common Norwegian seaweeds and evaluation of their potential as food and feed. J. Sci. Food Agric. 2014, 94, 3281-3290. [CrossRef]

45. Badmus, U.O.; Taggart, M.; Boyd, K.G. The effect of different drying methods on certain nutritionally important chemical constituents in edible brown seaweeds. J Appl. Phycol. 2019, 31, 3883-3897. [CrossRef]

46. Bradford, M.M. A rapid and sensitive method for the quantification of microgram quantities of protein utilizing the principle of protein-dye binding. Anal. Biochem. 1976, 72, 248-254. [CrossRef]

47. Mahoney, E.; Milewska, M.; Mironczuk-Chodakowska, I.; Terlikowska, K. The influence of carotenoid and chlorophyll content on the oxidative processes in the selected vegetable oils. Prog. Health Sci. 2018, 8, 144-151. [CrossRef]

48. Hupel, M.; Lecointre, C.; Meudec, A.; Poupart, N.; Gall, E.A. Comparison of photoprotective responses to UV radiation in the brown seaweed Pelvetia canaliculata and the marine angiosperm Salicornia ramosissima. J. Exp. Mar. Biol. Ecol. 2011, 401, 36-47. [CrossRef]

49. Abd El-Baky, H.H.; El Baz, F.K.; El-Baroty, G.S. Evaluation of marine alga Ulva lactuca L. as a source of natural preservative ingredient. Am. Eurasian J. Agric. Environ. Sci. 2008, 3, 434-444.

50. Wolff, J.P. Analysis and Determination of Lipids. In Analysis of Food Constituent; Multon, J.-L., Ed.; Wiley-VCH, Inc.: New York, NY, USA, 1997; Chapter 6; pp. 175-219. 
51. Jiménez-Escrig, A.; Gómez-Ordóñez, E.; Rupérez, P. Brown and red seaweeds as potential sources of antioxidant nutraceuticals. J. Appl. Phycol. 2012, 24, 1123-1132. [CrossRef]

52. López, A.; Rico, M.; Rivero, A.; de Tangil, M.S. The effects of solvents on the phenolic contents and antioxidant activity of Stypocaulon scoparium algae extracts. Food Chem. 2011, 125, 1104-1109. [CrossRef]

53. Saad, H.B.; Gargouri, M.; Kallel, F.; Chaabene, R.; Boudawara, T.; Jamoussi, K.; Magné, C.; Zeghal, K.M.; Hakim, A.; Ben Amara, I. Flavonoid compounds from the red marine alga Alsidium corallinum protect against potassium bromate-induced nephrotoxicity in adult mice. Environ. Toxicol. 2016, 32, 1475-1486. [CrossRef] [PubMed]

54. Murugan, K.; Iyer, V.V. Antioxidant and antiproliferative activities of extracts of selected red and brown seaweeds from the Mandapam Coast of Tamil Nadul. J. Food Biochem. 2014, 38, 92-101. [CrossRef]

55. Chebil, L.; Humeau, C.; Anthoni, J.; Dehez, F.; Engasser, J.-M.; Ghoul, M. Solubility of Flavonoids in Organic Solvents. J. Chem. Eng. Data 2007, 52, 1552-1556. [CrossRef]

56. Cox, S.; Abu-Ghannam, N.; Gupta, S. An assessment of the antioxidant and antimicrobial activity of six species of edible Irish seaweeds. Int. Food. Res. J. 2010, 17, 205-220.

57. Aladedunye, F.A. Natural antioxidants as stabilizers of frying oils. Eur. J. Lipid Sci. Technol. 2014, 116, 688-706. [CrossRef]

58. Brewer, M.S. Natural antioxidants: Sources, compounds, mechanisms of action, and potential applications. Compr. Rev. Food Sci. F 2011, 10, 221-247. [CrossRef]

59. Adwas, A.A.; Elsayed, A.; Azab, A.E.; Quwaydir, F.A. Oxidative stress and antioxidant mechanisms in human body. J. Appl. Biotechnol. Bioeng 2019, 6, 43-47.

60. Kubalt, K. The role of phenolic compounds in plant resistance. Biotechnol. Food Sci. 2016, 80, 97-108.

61. Yang, Y.; Song, X.; Sui, X.; Qi, B.; Wang, Z.; Li, Y.; Jiang, L. Rosemary extract can be used as a synthetic antioxidant to im-prove vegetable oil oxidative stability. Ind. Crops Prod. 2016, 80, 141-147. [CrossRef]

62. Siraj, N.; Shabbir, M.A.; Khan, M.R.; Rehman, K.U. Preventing oxidation of canola and sunflower oils by addition of pome-granate seed oil. Acta Aliment. 2019, 48, 18-27. [CrossRef]

63. Tinello, F.; Lante, A. Accelerated storage conditions effect on ginger- and turmeric-enriched soybean oils with comparing a synthetic antioxidant BHT. LWT 2020, 131, 109797. [CrossRef] 